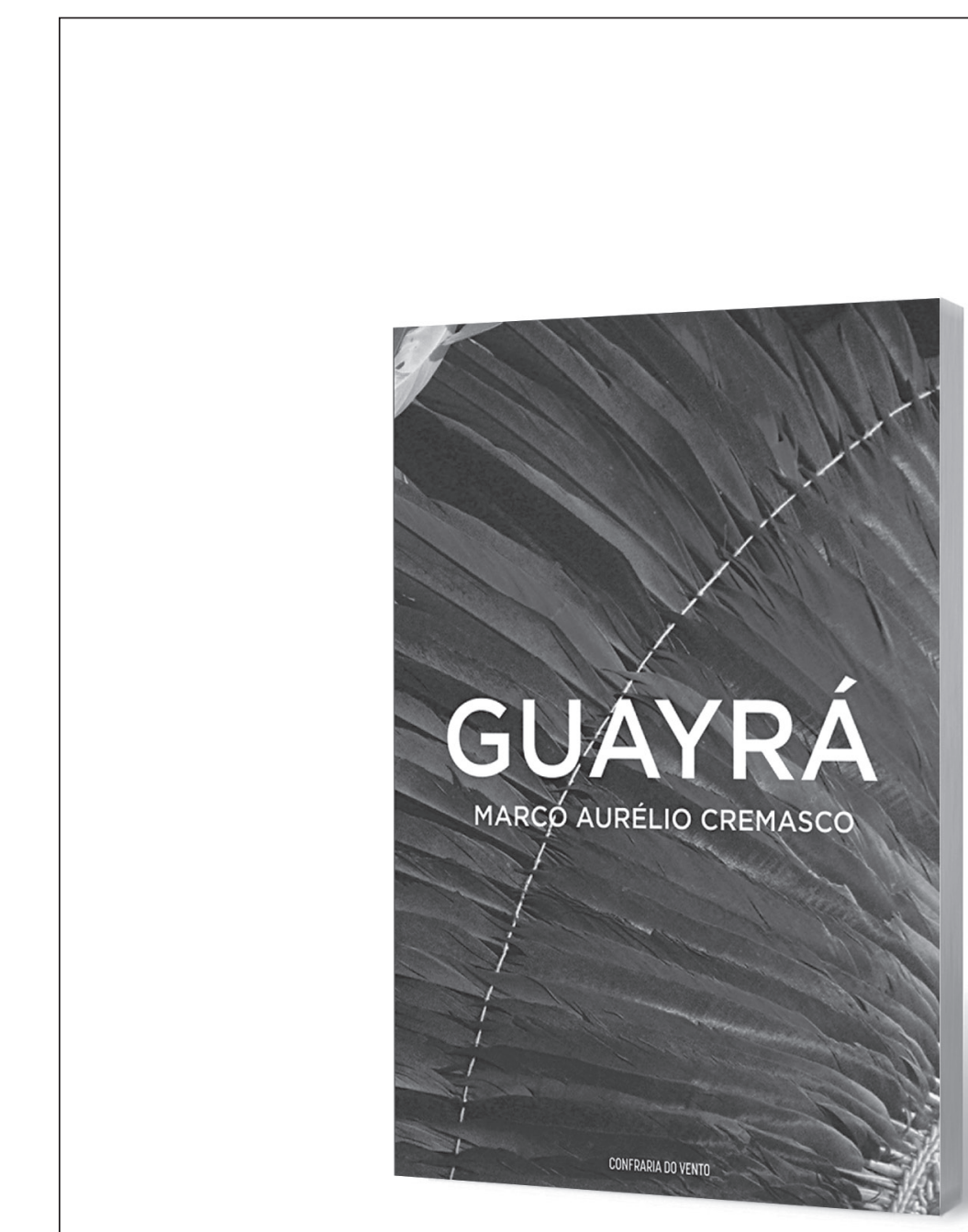

\title{
Sobre o romance Guayrá
}

\section{Antonio Riserio}

Guayrá, de Marco Aurélio Cremasco,

Rio de Janeiro, Confraria do Vento, 2017, 320 pp. 


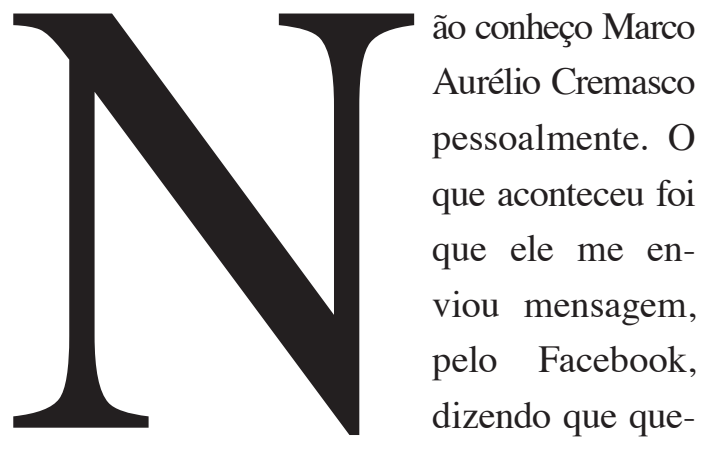

ria me mandar um romance de sua autoria.

Passei o endereço. Recebi o livro: Guayrá.

Depois de algum tempo, comecei a ler. E curti. Muito. É um romance que precisa ser mais conhecido em meio à comunidade geral dos leitores.

$\mathrm{Na}$ verdade, nesses dias de cretinices e fascismos "identitários" (neonegros, hiperfeministas, "trans-o-caralho-a-quatro", etc., etc.), quando tentam nos impor a estupidez de que a certidão de nascimento é mais importante do que a obra do escritor, confesso que é realmente um prazer encontrar um trabalho como Guayrá. Para dizer em duas palavras: um livro culto e belo.

Trata-se de um romance histórico que se passa nas primeiras décadas do século XVII, quando as "reduções" ou "missões" jesuíticas se implantam no Guairá, com apoio inicial do governador espanhol do Paraguai. Em tela, basicamente, índios guaranis (e seus implacáveis inimigos tupis), missionários da Companhia de Jesus e mamelucos paulistas. Personalidades históricas reais fazem ponta ou mesmo têm desempenhos consideráveis na narrativa. Como o governador Hernandarías de Saavedra, os jesuítas Cataldino e Maceta, Amador Bueno, o bandeirante judeu Raposo Tavares, o cacique Tayaová, etc. Mas, sobretudo, o grande jesuíta Antonio Ruiz de Montoya, que, no início da narrativa, está compondo o seu hoje célebre dicionário da língua guarani.

Por falar nisso, é bem verdade que, para um leitor chato como eu, Guayrá chama por alguns pequenos ajustes ou reparos de natureza histórica e antropológica. No plano histórico, por exemplo, é algo estranha a

ANTONIO RISERIO é poeta, antropólogo e romancista. É autor de, entre outros, Que Você É Esse? (Record). 
raiva de judeus contra jesuítas. Afinal, a Companhia de Jesus se opôs muitas vezes à Inquisição. E o jesuíta Antônio Vieira foi frontalmente contrário à expulsão dos judeus de Portugal. Aliás, Vieira foi preso pelo Tribunal do Santo Ofício.

Um outro aspecto histórico é que o leitor sai do livro com a crença de que as reduções missionárias foram destroçadas definitivamente naquelas primeiras décadas do século XVII. E não foi exatamente isso o que aconteceu. As missões se estenderam, com êxito, até a expulsão dos jesuítas em 1768.

Antropologicamente, também, cabe talvez um reparo. Se não me falha a memória, os guaranis não estabeleciam uma conexão clara entre relação sexual e concepção. As crianças eram como que enviadas pelos deuses. No romance, todavia, os casais Atyguajé e Kuarasy e Itawerá e Potyporã mostram ter consciência de que a fecundação vem com o sexo. O que também pode ser visto, por outro lado, já como influência da cultura ocidental europeia, via colonização ibérica e proselitismo cristão.

Um outro lance é que às mulheres estava vedado o ingresso no topo das categorias ou da hierarquia dos xamãs guaranis. Já no romance, é linda (e não deixa de deleitar o leitor informado, até pelo sabor subversivo) a projeção de Maria Kuarasy como grande feiticeira.

Mas é claro que isso não é assim tão importante. São aspectos extraliterários. O que importa é que, no campo estrito do fazer romanesco, Guayrá é muito bom.

Entre tantas coisas dignas de nota no romance, cabe ressaltar a paisagem mitológica, com ênfase na Terra sem Mal - e o artesanato textual norteado pela visão guarani da dimensão estética da linguagem.
"A vida é a dança de Nhanderu, xera [...]." A beleza dos mitos e do fabulário guaranis. Muito interessante, também, ver como Cremasco lida com o culto dedicado aos ossos dos grandes xamãs, descoberto pelo jesuíta Montoya, que foi pelo menos o único a registrá-lo. No romance, esse traço próprio do sagrado guarani ganha todo o seu merecido destaque.

Impressiona, de outra parte, a viagem final do guerreiro Itawerá, incorporando tudo pelo espaço devastado das primeiras missões, ao tempo em que avança em direção ao mar, buscando a Terra sem Mal (a utopia guarani - paraíso da eterna juventude; mundo de festa, não de trabalho, onde o milho cresce por si e as flechas saem sozinhas para caçar).

Na verdade, a Terra sem Mal é a expressão guarani de um sonho social da humanidade. Da vida num mundo ideal. Sonho encontrável nas mais variadas culturas e épocas históricas. Como nas utopias populares da Idade Média, por exemplo: Cucanha, Pomona, Hy Brasil...

E é evidente que um escritor dedicado ao trato textual, como é o caso de Cremasco, não teria como não se entregar ao fascínio da teoria guarani da palavra e do texto estético.

$\tilde{N} e^{\prime} \dddot{e}$ é a expressão guarani para "alma" e "palavra". Deve ser traduzida, mesmo, por alma-palavra. É esta alma-palavra que se encarna em nós, na primeira infância. E a morte é a perda da palavra.

Já a teoria guarani da linguagem poética se concentra na artificialização estética do discurso. Quando se fala de "linguagem enfeitada" ou "linguagem bela", na cultura guarani, o "belo" verbal é visto como fenômeno que só vem à luz em decorrência da práxis. Essa diferença é bem marcada, por sinal, não 
só pelo texto criativo guarani resultar de um trabalho realizado na fala, como por empregar palavras-conceitos que não são utilizadas no comércio diário dos signos.

Eloquência que, em Guayrá, não se restringe ao raconto de mitos e fábulas. Permeia todo o texto, chegando a alguns pontos altos, como no sermão xamânico-profético do je- suíta Primo Oscar, inspirado por Mba'ekuaá, figura da sabedoria.

Mas, para degustar o romance, é necessária uma espécie de paciência fascinada. Aqui, estamos longe do realismo estrito - e muitos temas e nomes de personagens não são familiares ao leitor comum. Quem tiver a dita paciência, no entanto, só terá a ganhar. 